\title{
Pontos críticos de controle na qualidade higiênico-sanitária do preparo de sushis e sashimis no município de São Vicente, São Paulo.
}

\author{
Bárbara Grassi Prado ${ }^{1}$, Juliana Elen Iwatani ${ }^{2}$, Mariana Rotta Pereira ${ }^{2}$, Andréa Pittelli Boiago \\ Gollucke $^{2}$ e Luciana Passos Toledo ${ }^{2}$
}

\begin{abstract}
Este estudo objetivou propor um plano de Análise dos Perigos e Pontos Críticos (APPCC) de controle na produção de sushis $e$ sashimis. Trata-se de um estudo descritivo realizado em um restaurante japonês em São Vicente - SP, em 2007. A coleta de dados foi realizada a partir da observação do preparo de sushis e sashimis no sushibar. Foram identificados os principais ingredientes e as etapas de produção, possibilitando aplicar os sete princípios do APPCC. Os critérios para produção de alimentos seguros foram propostos com base nas leis vigentes. O pescado cru, arroz, camarão e polvo cozidos, as frutas e hortaliças cruas, a alga nori e o kani-kama são os principais ingredientes do sushi e os pescados crus, do sashimi. Foram identificados treze pontos críticos de controle, sendo o pescado cru a maior preocupação para a saúde do consumidor, pois não possui etapa de eliminação de contaminantes microbiológicos. A etapa de montagem e porcionamento do sushi e do sashimi, deve ser monitorada para não haver contaminação do alimento pelas mãos do sushiman, pelos equipamentos, utensílios e bancadas utilizadas. Com o intuito de adequar as preparações aos procedimentos de controle higiênico-sanitário, preservando-se características peculiares da culinária japonesa, sugerese a elaboração de leis específicas para preparações típicas, como os sushis e sashimis.
\end{abstract}

Palavras-chave: Análise dos Perigos em Pontos Críticos e de Controle, higiene dos alimentos, manipulação de alimentos, pescados.

\section{Critical control points in sanitary conditions of the preparation of sushi and sashimi in São Vicente, São Paulo.}

This study aimed to propose a plan for Hazard Analysis and Critical Control Points (HACCP) the production of sushi and sashimi. This is a descriptive study in the Japanese restaurant in São Vicente - SP in 2007. Data collection was performed by observing the preparation of sushi and sashimi at the sushibar. The main ingredients and production stages, allowing to apply the seven principles of HACCP have been identified. The criteria for safe food production have been proposed based on existing laws. The raw fish, rice, boiled shrimp and octopus, raw fruits and vegetables, nori seaweed and kani-kama are the main ingredients of sushi and raw fish of sashimi. Thirteen critical control points were identified and the biggest concern for the health is the raw fish, because it has no elimination of microbiological contaminants. The step assembly and portioning of sushi and sashimi, deserves special attention for no contamination of food by the hands of the sushiman, the equipment, utensils and countertops used. With the pupose of making preparations procedures for hygienicsanitary control, preserving the peculiar characteristics of Japanese cuisine, we suggest the development of specific laws for typical preparations, such as sushi and sashimi.

\footnotetext{
${ }^{1}$ Departamento de Epidemiologia, Faculdade de Saúde Pública/USP. Correspondência: Av. Dr. Arnaldo no 715, CEP 01246-904 - Cerqueira César, São Paulo, SP. Telefones (13) 8868-6866 / (65) 8469-7668. E-mail: barbaragrassi@usp.com

${ }^{2}$ Faculdade de Nutrição. Universidade Católica de Santos.
} 
Key-words: Hazard Analysis and Critical Control Point, Food Hygiene, Food Handling, Fishes.

\section{INTRODUÇÃO}

A gastronomia de determinados povos ou regiões, por meio dos seus pratos típicos, fornecem-lhe uma identidade étnica, que refletem a história de seu povo, suas tradições e peculiaridades locais, sendo considerada como um patrimônio gastronômico ${ }^{[1,2]}$.

Por meio da globalização e do processo de imigração, diversos países passaram a compartilhar suas culturas, incluindo a gastronomia. Assim, é crescente o número de pessoas que buscam conhecer gastronomias internacionais, experimentando diferentes pratos típicos. No Brasil, podem-se encontrar restaurantes de gastronomias internacionais, como a italiana, francesa, árabe, mexicana, japonesa, e muitos outros tipos [2,3].

Há mais de 100 anos, ocorreu a imigração japonesa ao Brasil, em que famílias japonesas chegavam ao país com intuito de trabalhar nas fazendas de café. Estas famílias trouxeram consigo suas tradições e cultura, entre elas, a sua culinária [4], que caracteriza-se pela utilização de alimentos naturais como os vegetais de modo geral e pescados, além dos temperos, arroz, algas e produtos da soja [5. Dentre as diversas preparações da culinária japonesa, estão os sushis e sashimis. O sushi é a combinação do arroz japonês, preparado com vinagre de arroz, com pescados crus, que pode incluir a alga nori (folhas finas e secas, feitas a partir da desidratação de algas comestíveis da espécie Porphyra), frutas, hortaliças e o kani-kama (alimento a base de peixe com sabor artificial de carne de caranguejo), além de diversos acompanhamentos como a raiz forte (wasabi) e o gengibre. O sashimi é todo alimento marítimo consumido cru, como peixe, marisco, camarões, lula, entre outros. O sushiman é o responsável pela produção destas preparações $[5,0]$.

Geralmente, estas preparações são comercializadas em restaurantes típicos, como os restaurantes especializados em culinária japonesa, que possuem área exclusiva para o preparo de sushis e sashimis, denominada sushibar [5], mas também podem ser encontradas em restaurantes comuns, como parte integrante de cardápios variados [3]. Os restaurantes típicos são mais valorizados, pois apresentam um pouco da história local e são as melhores referências para o consumo de ingredientes regionais $[7]$.

Segundo dados do Ministério da Pesca e Aquicultura, a média de consumo anual de pescados por habitante ano no País alcançou 11,17 quilos em 2011, o equivalente a 15\% a mais em relação ao ano de 2010. Já entre 2009 e 2010 o ritmo de crescimento da demanda foi de 7,9\%. Nos anos de 2010 e 2011, o crescimento da demanda por peixes e frutos do mar aumentou em média 23,7\% [8]. Por isto, estas preparações merecem especial atenção na sua qualidade higiênico-sanitária, garantindo a produção de um alimento seguro ao consumo humano.

Todo estabelecimento produtor de alimentos deve adotar procedimentos para garantir a qualidade higiênico-sanitária dos alimentos produzidos, denominado Boas Práticas. A adoção das Boas Práticas possui como finalidade assegurar que o alimento produzido seja seguro e desta forma, livre de perigos, que são contaminantes inaceitáveis nos alimentos, como a presença de contaminantes físicos (pedras, plásticos), químicos (produtos de limpeza) e microbiológicos (microrganismos causadores de doenças), evitando-se assim, as Doenças Transmitidas por Alimentos (DTAs) [9].

Os estabelecimentos também devem adotar o sistema APPCC (Análise de Perigos e Pontos Críticos de Controle), que identifica, avalia e controla perigos que são significativos para a segurança de alimentos, por meio da elaboração do Plano APPCC [10]. No Brasil, sua implantação foi estabelecida como obrigatória às indústrias, pela Portaria no 1.428, de 26 de novembro de 1993, do Ministério da Saúde [11].

O Plano APPCC é um documento elaborado com base em sete princípios, baseados na identificação e avaliação dos perigos e estratégias para identificação e controle dos pontos críticos de controle (PCC), que são pontos, etapas ou procedimentos nos quais uma medida de controle pode ser aplicada e um perigo pode ser eliminado, prevenido ou reduzido a níveis aceitáveis. As etapas de produção que não são caracterizadas como PCC, são denominadas pontos de controle (PC) ${ }^{[10] .}$ 
A literatura aponta para a importância da implementação do sistema APPCC na produção de alimentos, que abrange a indústria alimentícia $[12,13,14,15]$ até a produção de alimentos em restaurantes e estabelecimentos comerciais $[16,17,18]$.

Na produção de sushis e sashimis, a adoção de Boas Práticas e a implantação do APPCC são essenciais para garantir a qualidade higiênico-sanitárias destes alimentos, principalmente devido à presença dos pescados crus, que possuem características intrínsecas necessárias à proliferação de microrganismos patogênicos, como $\mathrm{pH}$ próximo à neutralidade, elevada atividade de água e elevado teor de nutrientes [19]. Existem vários microrganismos patogênicos encontrados em pescados crus, entre eles, destacam-se os coliformes totais, Escherichia coli, Stapbylococcus spp, Salmonella spp, Vibrio spp, Aeromonas spp [20].

Menezes et al. ${ }^{[21]}$ analisaram 10 pares de sushis e sashimis de dois restaurantes de Fortaleza/CE e detectaram 5 amostras de sushis e 5 de sashimis com Salmonella, 5 amostras de sushis e 4 de sashimis com Staphylococcus, e 2 amostras de sushi e 2 de sashimi estavam contaminadas com Salmonella e Staphylococcus ao mesmo tempo. Rodrigues et al. [22] analisaram pescados crus utilizados em sushis e sashimis e encontraram 13\% das preparações com alguma alteração de $\mathrm{pH}$, amônia e histamina, além de todas as amostras apresentarem-se expostas fora da temperatura adequada.

Rocha et al. [23] avaliaram as condições de entrega de pescados por fornecedores de um restaurante de comida japonesa e observaram que somente $2,7 \%$ da amostra de atum e 3,1\% da amostra de namorado encontravam-se dentro da faixa de temperatura preconizada, de até $4^{\circ} \mathrm{C}$.

Mársico et al. [24] analisaram o teor de histamina em 50 amostras de pescados utilizados na produção de sushis e sashimis no Rio de Janeiro e observaram que $44 \%$ das amostras estavam acima dos limites recomendados.

Huang et al. [25] analisaram amostras de sushis produzidos em supermercados da China antes e após a implantação do APPCC e observaram aumento de $32,8 \%$ para $82,2 \%$ na proporção de amostras seguras ao consumo.

Atanassova et al. [26] analisaram amostras de sushis prontos para consumo e elaborados no momento do consumo, e verificaram que os sushis prontos para consumo possuem melhor controle de qualidade e assim, os produtores de sushis frescos devem ser melhor capacitados a fim de produzirem alimentos seguros.

Com o intuito de incentivar o consumo de pratos típicos, como os sushis e sashimis, que possuem valores culturais e nutricionais, e garantir a oferta de alimentos seguros para consumo, o presente estudo teve como objetivo propor um plano de Análise dos Perigos e Pontos Críticos de Controle na produção de sushis e sashimis.

\section{MATERIAL E MÉTODOS}

Trata-se de um estudo descritivo realizado em um restaurante de culinária japonesa localizado no município de São Vicente, no estado de São Paulo, em 2007. A coleta de dados foi realizada no mês de fevereiro, durante dois dias da semana, por meio da observação do preparo de sushis e sashimis no sushibar, área destinada à produção destas preparações.

Foram identificados os principais ingredientes das preparações e as etapas de produção. Com base no fluxograma de produção foi possível aplicar os sete princípios do APPCC. Princípio 1: identificação dos possíveis perigos biológicos, químicos e físicos para a saúde do cliente em cada etapa do processo de produção dos sushis e sashimis, Princípio 2: identificação dos Pontos Críticos de Controle - PCC, utilizando-se como ferramenta o diagrama decisório adaptado do Codex Alimentarius [10]; Princípio 3: Estabelecimento dos limites críticos para cada PCC; Princípio 4: os procedimentos de monitorização dos PCC; Princípio 5: estabelecimento das ações corretivas a serem adotadas quando o monitoramento indicar que um PCC não está sob controle; Princípio 6: estabelecimento dos procedimentos de verificação; Princípio 7: estabelecimento dos procedimentos de registro.

Os critérios para produção de alimentos seguros foram propostos com base nas legislações CVS-5/2013 [9] e RDC 216/2004 [27]. As etapas que podem ser controladas pelas Boas Práticas foram consideradas Pontos de Controle (PC). Os PCC, que são pontos, etapas ou procedimentos nos quais uma medida de controle pode ser aplicada e um perigo pode ser eliminado (PCCe) ou prevenido (PCCp), foram classificados em PCCe e PCCp. 
O responsável pelo estabelecimento assinou um Termo de Consentimento Livre e Esclarecido, autorizando a coleta de dados. Por se tratar da observação de preparações, este estudo não foi encaminhado ao Comitê de Ética em Pesquisa.

\section{RESULTADOS E DISCUSSÃO}

Este estudo objetivou propor um plano de Análise dos Perigos e Pontos Críticos de Controle na produção de sushis e sashimis.

A observação das preparações realizadas no sushibar possibilitou a identificação dos ingredientes utilizados no preparo de sushis e sashimis. O sushi era preparado utilizando-se peixe cru (salmão, atum, robalo, tainha e agulhão), arroz japonês, camarão e polvo cozidos, as frutas (manga, morango, maçã e carambola) e hortaliças cruas (acelga, alface, beterraba, cenoura, nabo e pepino), a alga nori e o kani-kama. Para fazer o sashimi, utilizaram-se os seguintes pescados crus: salmão, atum, robalo, tainha, agulhão, camarão e polvo.

A Figura 1 mostra o fluxograma de produção do sushi e a Figura 2, o fluxograma de produção do sashimi. No Quadro 1, estão descritos os PC e os PCC, perigos e medidas preventivas na produção de sushis e sashimis. Foram identificados treze PCC, cujos limites críticos, formas de monitorização, ações corretivas, verificação e registro, foram propostos e detalhados no plano de análise, constante no Quadro 2.

Figura 1. Fluxograma do preparo do sushi. São Vicente, SP, 2007.

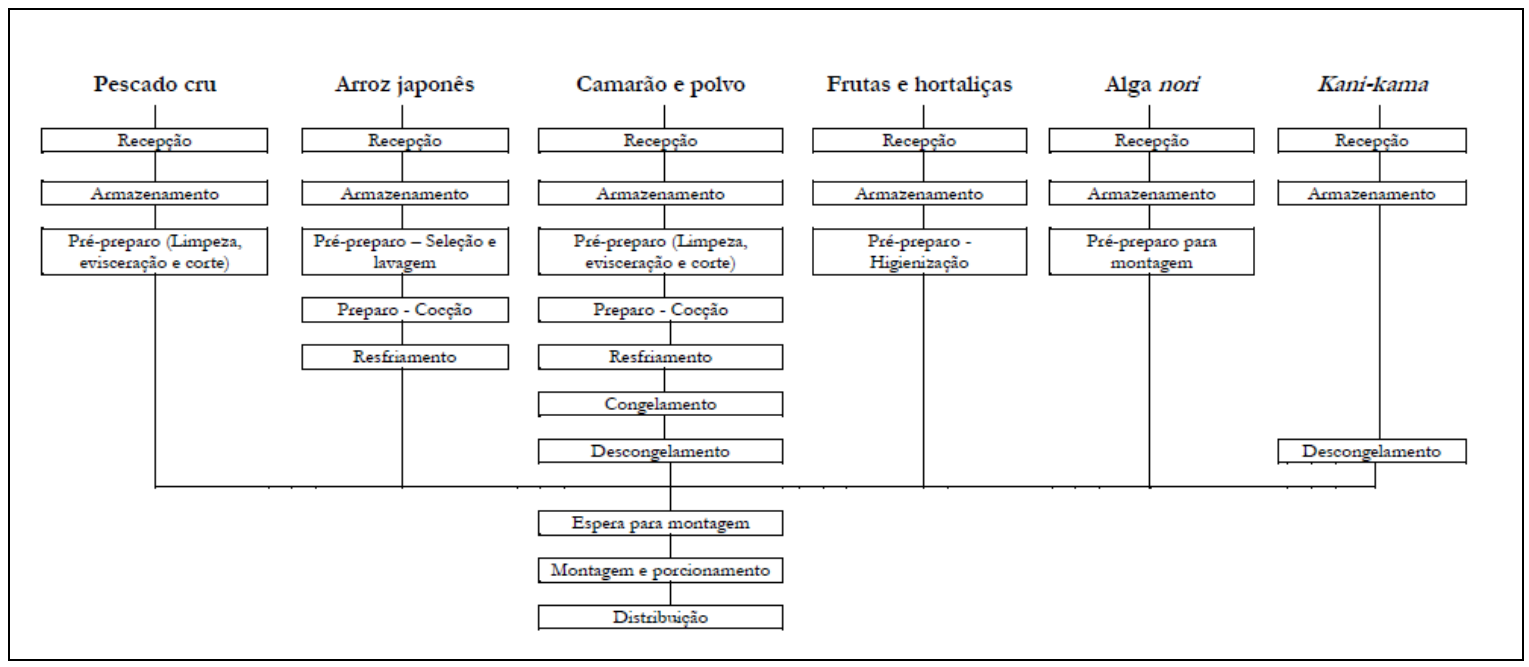

Figura 2. Fluxograma do preparo do sashimi. São Vicente, SP, 2007.

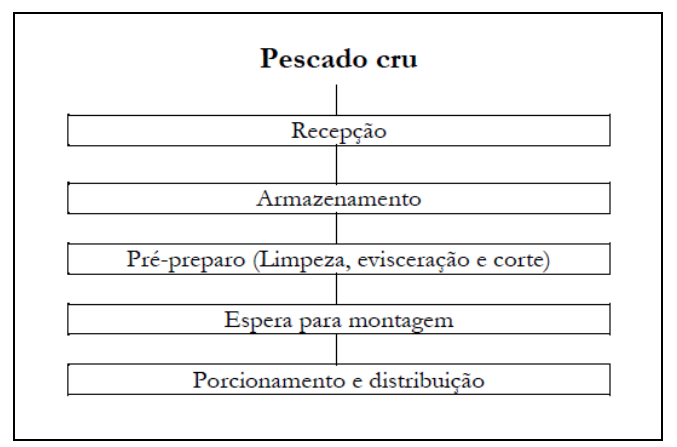


Quadro 1. Identificação dos Pontos Críticos de Controle, perigos e medidas preventivas na produção de sushis e sashimis. São Vicente, SP, 2007.

\begin{tabular}{|c|c|c|c|c|}
\hline Alimento & Etapa & PC/PCC & Perigo & Medidas Preventivas \\
\hline \multirow{4}{*}{ Pescado cru } & Recepção & PC & $\begin{array}{l}\text { Contaminantes } \\
\text { microbiológicos }\end{array}$ & $\begin{array}{l}\text { O pescado deve estar entre } 2 \text { e } 3^{\circ} \mathrm{C} \text {; Observar as } \\
\text { características organolépticas (pele lisa, olhos vivos, } \\
\text { carne consistente). }\end{array}$ \\
\hline & Armazenamento & PC & $\begin{array}{l}\text { Contaminantes } \\
\text { microbiológicos }\end{array}$ & Manter sob refrigeração em até $2^{\circ} \mathrm{C}$ por até 3 dias. \\
\hline & $\begin{array}{l}\text { Pré-preparo (limpeza, } \\
\text { evisceração e corte) }\end{array}$ & PCCp1 & $\begin{array}{l}\text { Contaminantes } \\
\text { microbiológicos }\end{array}$ & $\begin{array}{l}\text { Realizar procedimento utilizando pequenos lotes por } \\
\text { no máximo } 30 \text { minutos. } \\
\text { Realizar antissepsia das mãos e higienizar corretamente } \\
\text { equipamentos e utensílios. }\end{array}$ \\
\hline & Espera para montagem & PCCp2 & $\begin{array}{l}\text { Contaminantes } \\
\text { microbiológicos }\end{array}$ & Manter sob refrigeração em até $2^{\circ} \mathrm{C}$ por até 3 dias. \\
\hline \multirow{6}{*}{ Arroz } & Recepção & PC & $\begin{array}{l}\text { Contaminantes } \\
\text { microbiológicos }\end{array}$ & $\begin{array}{l}\text { Pode ocorrer em temperatura ambiente; Deve-se } \\
\text { observar o prazo de validade e as condições da } \\
\text { embalagem (limpa e íntegra). }\end{array}$ \\
\hline & Armazenamento & PC & $\begin{array}{l}\text { Contaminantes } \\
\text { microbiológicos }\end{array}$ & $\begin{array}{l}\text { Deve ser mantido em temperatura ambiente; controlar } \\
\text { vetores e pragas urbanas. }\end{array}$ \\
\hline & $\begin{array}{c}\text { Pré-preparo (seleção e } \\
\text { lavagem) }\end{array}$ & PC & Contaminantes físicos & $\begin{array}{l}\text { Realizar seleção dos possíveis contaminantes físicos } \\
\text { (pedras e sujidades) e lavar em água potável. }\end{array}$ \\
\hline & Preparo (cocção) & PCCe3 & $\begin{array}{l}\text { Contaminantes } \\
\text { microbiológicos }\end{array}$ & $\begin{array}{l}\text { No processo de cocção, o alimento deve atingir } 74^{\circ} \mathrm{C} \\
\text { no seu centro geométrico. }\end{array}$ \\
\hline & Resfriamento & PCCp4 & $\begin{array}{l}\text { Contaminantes } \\
\text { microbiológicos }\end{array}$ & $\begin{array}{l}\mathrm{O} \text { alimento deve reduzir de } 60^{\circ} \mathrm{C} \text { para } 10^{\circ} \mathrm{C} \text { em no } \\
\text { máximo } 2 \text { horas e ser refrigerado até } 4^{\circ} \mathrm{C} \text {. A } \\
\text { temperatura deve ser monitorada por meio de } \\
\text { termômetros. }\end{array}$ \\
\hline & Espera para montagem & PCCp5 & $\begin{array}{l}\text { Contaminantes } \\
\text { microbiológicos }\end{array}$ & $\begin{array}{l}\text { Manter sob refrigeração de até } 4^{\circ} \mathrm{C} \text { por } 3 \text { dias. Manter } \\
\text { em pequenos lotes para a utilização conforme } \\
\text { necessário. }\end{array}$ \\
\hline \multirow{8}{*}{$\begin{array}{l}\text { Camarão e } \\
\text { polvo cozidos }\end{array}$} & Recepção & PC & $\begin{array}{l}\text { Contaminantes } \\
\text { microbiológicos }\end{array}$ & $\begin{array}{l}\text { Os pescados devem estar entre } 2 \text { e } 3^{\circ} \mathrm{C} \text {; Observar as } \\
\text { características organolépticas (pele lisa, olhos vivos, } \\
\text { carne consistente). }\end{array}$ \\
\hline & Armazenamento & PC & $\begin{array}{l}\text { Contaminantes } \\
\text { microbiológicos }\end{array}$ & Manter sob refrigeração de até $2^{\circ} \mathrm{C}$ por 3 dias. \\
\hline & $\begin{array}{l}\text { Pré-preparo (limpeza, } \\
\text { evisceração e corte) }\end{array}$ & PC & $\begin{array}{l}\text { Contaminantes } \\
\text { microbiológicos }\end{array}$ & $\begin{array}{l}\text { Realizar procedimento utilizando pequenos lotes por } \\
\text { no máximo } 30 \text { minutos. } \\
\text { Realizar antissepsia das mãos e higienizar corretamente } \\
\text { equipamentos e utensílios. }\end{array}$ \\
\hline & Preparo (cocção) & PCCe6 & $\begin{array}{l}\text { Contaminantes } \\
\text { microbiológicos }\end{array}$ & $\begin{array}{l}\text { No processo de cocção, o alimento deve atingir } 74^{\circ} \mathrm{C} \\
\text { no seu centro geométrico. }\end{array}$ \\
\hline & Resfriamento & PCCp7 & $\begin{array}{l}\text { Contaminantes } \\
\text { microbiológicos }\end{array}$ & $\begin{array}{l}\mathrm{O} \text { alimento deve reduzir de } 60^{\circ} \mathrm{C} \text { a } 10^{\circ} \mathrm{C} \text { em no } \\
\text { máximo } 2 \text { horas e ser refrigerado até } 2^{\circ} \mathrm{C} \text {. A } \\
\text { temperatura deve ser monitorada por meio de } \\
\text { termômetros. }\end{array}$ \\
\hline & Congelamento & PC & $\begin{array}{l}\text { Contaminantes } \\
\text { microbiológicos }\end{array}$ & $\begin{array}{l}\mathrm{O} \text { alimento deve atingir temperatura abaixo de } 0^{\circ} \mathrm{C} \text { em } \\
6 \text { horas ou menos. Congelar em pequenos lotes. }\end{array}$ \\
\hline & Descongelamento & PCCp8 & $\begin{array}{l}\text { Contaminantes } \\
\text { microbiológicos }\end{array}$ & $\begin{array}{l}\text { O descongelamento do alimento deverá ser efetuado } \\
\text { segundo a recomendação do fabricante. Na ausência, } \\
\text { pode ser realizado em forno de micro-ondas ou sob } \\
\text { refrigeração, em temperatura inferior a } 5^{\circ} \mathrm{C} \text {. Após o } \\
\text { descongelamento o alimento deve ficar sob } \\
\text { refrigeração até } 2^{\circ} \mathrm{C} \text {. }\end{array}$ \\
\hline & Espera para montagem & PCCp9 & $\begin{array}{l}\text { Contaminantes } \\
\text { microbiológicos }\end{array}$ & Manter sob refrigeração de até $2^{\circ} \mathrm{C}$ por 1 dia. \\
\hline
\end{tabular}




\section{Quadro 1. Continuação}

\begin{tabular}{|c|c|c|c|c|}
\hline \multirow{4}{*}{$\begin{array}{l}\text { Frutas e } \\
\text { hortaliças } \\
\text { cruas }\end{array}$} & Recepção & PC & $\begin{array}{l}\text { Contaminantes } \\
\text { microbiológicos }\end{array}$ & $\begin{array}{l}\text { Observar as características organolépticas (devem estar } \\
\text { integras e firmes). }\end{array}$ \\
\hline & Armazenamento & PC & $\begin{array}{l}\text { Contaminantes } \\
\text { microbiológicos }\end{array}$ & Devem ser mantidas em temperatura de até $5^{\circ} \mathrm{C}$ por 3 dias. \\
\hline & Pré-preparo (higienização) & PCCe10 & $\begin{array}{l}\text { Contaminantes } \\
\text { microbiológicos }\end{array}$ & $\begin{array}{l}\text { Deve ser feita em local apropriado, com água potável e } \\
\text { produtos desinfetantes para uso em alimentos, regularizados } \\
\text { na ANVISA. Devem-se atender às instruções recomendadas } \\
\text { pelo fabricante. } \\
\text { A higienização deve contemplar: } \\
\text { - Lavagem criteriosa com água potável (incluindo a remoção } \\
\text { mecânica de partes deterioradas e de sujidades); } \\
\text { - Desinfecção: imersão em solução clorada por } 15 \text { a } 30 \\
\text { minutos ( } 10 \mathrm{~mL} \text { ou } 1 \text { colher de sopa rasa de hipoclorito de } \\
\text { sódio na concentração de } 2 \text { a } 2,5 \% \text { ou } 20 \mathrm{~mL} \text { ou } 2 \text { colheres de } \\
\text { sopa rasas de hipoclorito de sódio na concentração de } 1 \% \text {, } \\
\text { diluídas em um litro de água potável); } \\
\text { - Enxágue em água potável. } \\
\text { A cenoura e a beterraba devem ser descascadas. }\end{array}$ \\
\hline & Espera para montagem & PC & $\begin{array}{l}\text { Contaminantes } \\
\text { microbiológicos }\end{array}$ & Manter sob refrigeração de até $10^{\circ} \mathrm{C}$ por 3 dias. \\
\hline \multirow{3}{*}{ Alga nori } & Recepção & PC & $\begin{array}{l}\text { Contaminantes } \\
\text { microbiológicos }\end{array}$ & $\begin{array}{l}\text { Pode ocorrer em temperatura ambiente; Deve-se observar o } \\
\text { prazo de validade e as condições da embalagem (limpa e } \\
\text { íntegra). }\end{array}$ \\
\hline & Armazenamento & PC & $\begin{array}{l}\text { Contaminantes } \\
\text { microbiológicos }\end{array}$ & $\begin{array}{l}\text { Deve ser mantida em temperatura entre } 22^{\circ} \mathrm{C} \text { e } 26^{\circ} \mathrm{C} \text {; } \\
\text { controlar vetores e pragas urbanas. }\end{array}$ \\
\hline & Pré-preparo para Montagem & PCCp11 & $\begin{array}{l}\text { Contaminantes } \\
\text { microbiológicos }\end{array}$ & Higienizar as embalagens fechadas utilizando álcool $70 \%$. \\
\hline \multirow{3}{*}{ Kani-kama } & Recepção & PC & $\begin{array}{l}\text { Contaminantes } \\
\text { microbiológicos }\end{array}$ & $\begin{array}{l}\mathrm{O} \text { alimento deve estar a }-12^{\circ} \mathrm{C} \text { ou menos, ou conforme } \\
\text { especificação do fabricante. }\end{array}$ \\
\hline & Armazenamento & $\mathrm{PC}$ & $\begin{array}{l}\text { Contaminantes } \\
\text { microbiológicos }\end{array}$ & $\begin{array}{l}\mathrm{O} \text { alimento deverá ser armazenado sob congelamento: } 0 \text { a }- \\
5^{\circ} \mathrm{C} \text { durante } 10 \text { dias; }-6 \text { a }-10^{\circ} \mathrm{C} \text { em } 20 \text { dias; }-11 \text { a }-18^{\circ} \mathrm{C} \text { em } 30 \\
\text { dias; ou menor que }-18^{\circ} \mathrm{C} \text { em } 90 \text { dias. }\end{array}$ \\
\hline & Descongelamento & PCCp12 & $\begin{array}{l}\text { Contaminantes } \\
\text { microbiológicos }\end{array}$ & $\begin{array}{l}\text { O descongelamento do alimento deverá ser efetuado segundo } \\
\text { a recomendação do fabricante. Na ausência, pode ser realizado } \\
\text { em forno de micro-ondas ou sob refrigeração, em temperatura } \\
\text { inferior a } 5^{\circ} \mathrm{C} \text {. Após o descongelamento o alimento deve ficar } \\
\text { sob refrigeração até } 2^{\circ} \mathrm{C} \text {. }\end{array}$ \\
\hline \multirow[t]{2}{*}{ Susbi/Sasbimi } & $\begin{array}{l}\text { Montagem e } \\
\text { Porcionamento }\end{array}$ & PCCp13 & $\begin{array}{l}\text { Contaminantes } \\
\text { microbiológicos }\end{array}$ & $\begin{array}{l}\text { Realizar a antissepsia das mãos dos manipuladores; manipular } \\
\text { alimentos em lotes por } 30 \text { minutos; higienizar corretamente } \\
\text { utensílios e equipamentos (tábuas, bancadas e facas). }\end{array}$ \\
\hline & Distribuição & PC & $\begin{array}{l}\text { Contaminantes } \\
\text { microbiológicos }\end{array}$ & $\begin{array}{l}\text { Devem ser mantidos em temperatura de } 10^{\circ} \mathrm{C} \text { até } 4 \text { horas ou } \\
\text { entre } 10 \text { e } 21^{\circ} \mathrm{C} \text { por até } 2 \text { horas. }\end{array}$ \\
\hline
\end{tabular}


Quadro 2. Plano de análise dos Pontos Críticos de Controle na produção de sushis e sashimis. São Vicente, SP, 2007.

\begin{tabular}{|c|c|c|c|c|c|c|c|}
\hline Alimento & Etapa & PCC & Limite Crítico & Monitorização & Ação Corretiva & Verificação & Registro \\
\hline \multirow[b]{2}{*}{ Pescado cru } & Pré-preparo & PCCp1 & $\begin{array}{l}\text { Utilizar pequenos lotes } \\
\text { por no máximo } 30 \\
\text { minutos. } \\
\text { Realizar antissepsia das } \\
\text { mãos e higienizar } \\
\text { corretamente equipa- } \\
\text { mentos e utensílios. }\end{array}$ & $\begin{array}{l}\text { O que? Tempo de } \\
\text { manipulação do pescado } \\
\text { cru } \\
\text { Quem? Sushiman } \\
\text { Como? Utilizando-se o } \\
\text { relogio. }\end{array}$ & $\begin{array}{l}\text { Reduzir o tamanho } \\
\text { dos lotes ou dividir o } \\
\text { pescado em partes } \\
\text { para reduzir o tempo } \\
\text { de manipulação. }\end{array}$ & $\begin{array}{lr}\text { Análise } & \text { micro- } \\
\text { biológica. } & \\
\text { Supervisão } & \mathrm{da} \\
\text { etapa. } & \end{array}$ & $\begin{array}{c}\text { Planilha } \\
\text { própria (1) }\end{array}$ \\
\hline & $\begin{array}{l}\text { Espera para } \\
\text { montagem }\end{array}$ & PCCp2 & $\begin{array}{l}\text { Manter em até } 2^{\circ} \mathrm{C} \text { por } \\
3 \text { dias. }\end{array}$ & $\begin{array}{l}\text { O que? Tempo de espera } \\
\text { para utilização do } \\
\text { pescado cru e temperatura } \\
\text { de armazenamento. } \\
\text { Quem? Sushiman } \\
\text { Como? Por meio de } \\
\text { etiquetas com data e } \\
\text { borário do preparo. E } \\
\text { aferir a temperatura } \\
\text { periodica-mente. }\end{array}$ & $\begin{array}{l}\text { Calibração dos ter- } \\
\text { mômetros. } \\
\text { Manutenção perió- } \\
\text { dica dos equipa- } \\
\text { mentos de refrige- } \\
\text { ração. }\end{array}$ & $\begin{array}{l}\text { Supervisão } \quad \mathrm{da} \\
\text { etapa. }\end{array}$ & $\begin{array}{c}\text { Planilha } \\
\text { própria (2) }\end{array}$ \\
\hline \multirow{3}{*}{ Arroz } & $\begin{array}{l}\text { Preparo } \\
\text { (cocção) }\end{array}$ & PCCe3 & $\begin{array}{l}\text { Atingir } 74^{\circ} \mathrm{C} \text { no centro } \\
\text { geométrico. }\end{array}$ & $\begin{array}{l}\text { O que? Temperatura do } \\
\text { arroz. } \\
\text { Quem? Sushiman } \\
\text { Como? Aferir a } \\
\text { temperatura } \\
\text { periodicamente. }\end{array}$ & $\begin{array}{l}\text { Calibração da panela } \\
\text { elétrica de arroz } \\
\text { japonês. } \\
\text { Calibração dos ter- } \\
\text { mômetros. }\end{array}$ & $\begin{array}{lr}\text { Análise } & \text { micro- } \\
\text { biológica. } & \\
\text { Supervisão } & \mathrm{da} \\
\text { etapa. } & \end{array}$ & $\begin{array}{c}\text { Planilha } \\
\text { própria (3) }\end{array}$ \\
\hline & $\begin{array}{l}\text { Resfria- } \\
\text { mento }\end{array}$ & PCCp4 & $\begin{array}{l}\mathrm{O} \text { alimento deve reduzir } \\
\text { de } 60^{\circ} \mathrm{C} \text { para } 10^{\circ} \mathrm{C} \text { em } \\
\text { no máximo } 2 \text { horas e ser } \\
\text { refrigerado até } 4^{\circ} \mathrm{C} \text {. }\end{array}$ & $\begin{array}{ll}\text { O que? Tempo } & e \\
\text { temperatura } & \text { do } \\
\text { resfriamento. } & \\
\text { Quem? Sushiman } & \\
\text { Como? Aferir a } \\
\text { temperatura } \\
\text { periodicamente. }\end{array}$ & $\begin{array}{l}\text { Calibração dos ter- } \\
\text { mômetros. }\end{array}$ & $\begin{array}{lr}\text { Análise } & \text { micro- } \\
\text { biológica. } & \\
\text { Supervisão } & \mathrm{da} \\
\text { etapa. } & \end{array}$ & $\begin{array}{c}\text { Planilha } \\
\text { própria (4) }\end{array}$ \\
\hline & $\begin{array}{l}\text { Espera para } \\
\text { montagem }\end{array}$ & PCCp5 & $\begin{array}{l}\text { Manter em até } 4^{\circ} \mathrm{C} \text { por } \\
3 \text { dias. }\end{array}$ & $\begin{array}{l}\text { O que? Tempo de } \\
\text { utilização do arroz } e \\
\text { temperatura de } \\
\text { armazenamento. } \\
\text { Quem? Sushiman } \\
\text { Como? Por meio de } \\
\text { etiquetas com data e } \\
\text { borário do preparo e } \\
\text { aferir a temperatura } \\
\text { periodica-mente. }\end{array}$ & $\begin{array}{lr}\text { Calibração } & \text { dos } \\
\text { termômetros. } & \\
\text { Manutenção } & \text { perió- } \\
\text { dica dos } & \text { equipa- } \\
\text { mentos de } & \text { refrige- } \\
\text { ração. } & \end{array}$ & $\begin{array}{l}\text { Supervisão } \quad \mathrm{da} \\
\text { etapa. }\end{array}$ & $\begin{array}{l}\text { Planilha } \\
\text { própria (5) }\end{array}$ \\
\hline \multirow{4}{*}{$\begin{array}{l}\text { Camarão e } \\
\text { polvo } \\
\text { cozidos }\end{array}$} & $\begin{array}{l}\text { Preparo } \\
\text { (cocção) }\end{array}$ & PCCe6 & $\begin{array}{l}\text { Atingir } 74^{\circ} \mathrm{C} \text { no centro } \\
\text { geométrico. }\end{array}$ & $\begin{array}{l}\text { O que? Temperatura do } \\
\text { pescado. } \\
\text { Quem? Sushiman } \\
\text { Como? Aferir a } \\
\text { temperatura } \\
\text { periodicamente. }\end{array}$ & $\begin{array}{l}\text { Calibração dos ter- } \\
\text { mômetros. }\end{array}$ & $\begin{array}{l}\text { Supervisão } \quad \mathrm{da} \\
\text { etapa. }\end{array}$ & $\begin{array}{c}\text { Planilha } \\
\text { própria (6) }\end{array}$ \\
\hline & Resfriamento & PCCp7 & $\begin{array}{l}\text { O alimento deve reduzir } \\
\text { de } 60^{\circ} \mathrm{C} \text { para } 10^{\circ} \mathrm{C} \text { em } \\
\text { no máximo } 2 \text { horas e ser } \\
\text { refrigerado até } 4^{\circ} \mathrm{C} \text {. }\end{array}$ & $\begin{array}{ll}\text { O que? Tempo } & e \\
\text { temperatura } & \text { do } \\
\text { resfriamento. } & \\
\text { Quem? Sushiman } & \\
\text { Como? Aferir a } \\
\text { temperatura } \\
\text { periodicamente. }\end{array}$ & $\begin{array}{l}\text { Calibração dos ter- } \\
\text { mômetros. }\end{array}$ & $\begin{array}{lr}\text { Análise } & \text { micro- } \\
\text { biológica. } & \\
\text { Supervisão } & \mathrm{da} \\
\text { etapa. } & \end{array}$ & $\begin{array}{l}\text { Planilha } \\
\text { própria (7) }\end{array}$ \\
\hline & $\begin{array}{l}\text { Descongela- } \\
\text { mento }\end{array}$ & PCCp8 & $\begin{array}{l}\text { Descongelamento } \\
\text { correto conforme } \\
\text { medidas preventivas. }\end{array}$ & $\begin{array}{l}\text { O que? Temperatura do } \\
\text { pes-cado } \\
\text { Quem? Sushiman } \\
\text { Como? Aferir a } \\
\text { temperatura } \\
\text { periodicamente. }\end{array}$ & $\begin{array}{l}\text { Calibração dos ter- } \\
\text { mômetros. }\end{array}$ & $\begin{array}{lr}\text { Análise } & \text { micro- } \\
\text { biológica. } & \\
\text { Supervisão } \\
\text { etapa. }\end{array}$ & $\begin{array}{l}\text { Planilha } \\
\text { própria (8) }\end{array}$ \\
\hline & $\begin{array}{l}\text { Espera para } \\
\text { montagem }\end{array}$ & PCCp9 & $\begin{array}{l}\text { Manter em até } 2^{\circ} \mathrm{C} \text { por } \\
1 \text { dia. }\end{array}$ & $\begin{array}{l}\text { O que? Tempo de espera } \\
\text { para utilização do } \\
\text { pescado e temperatura de } \\
\text { arma-zenamento. } \\
\text { Quem? Sushiman } \\
\text { Como? Por meio de } \\
\text { etiquetas com data e } \\
\text { borário do preparo e } \\
\text { aferir a temperatura } \\
\text { periodicamente. }\end{array}$ & $\begin{array}{l}\text { Calibração dos ter- } \\
\text { mômetros. } \\
\text { Manutenção perió- } \\
\text { dica dos equipa- } \\
\text { mentos de refrige- } \\
\text { ração. }\end{array}$ & $\begin{array}{l}\text { Supervisão } \quad \mathrm{da} \\
\text { etapa. }\end{array}$ & $\begin{array}{c}\text { Planilha } \\
\text { própria (9) }\end{array}$ \\
\hline
\end{tabular}


Quadro 2. Continuação

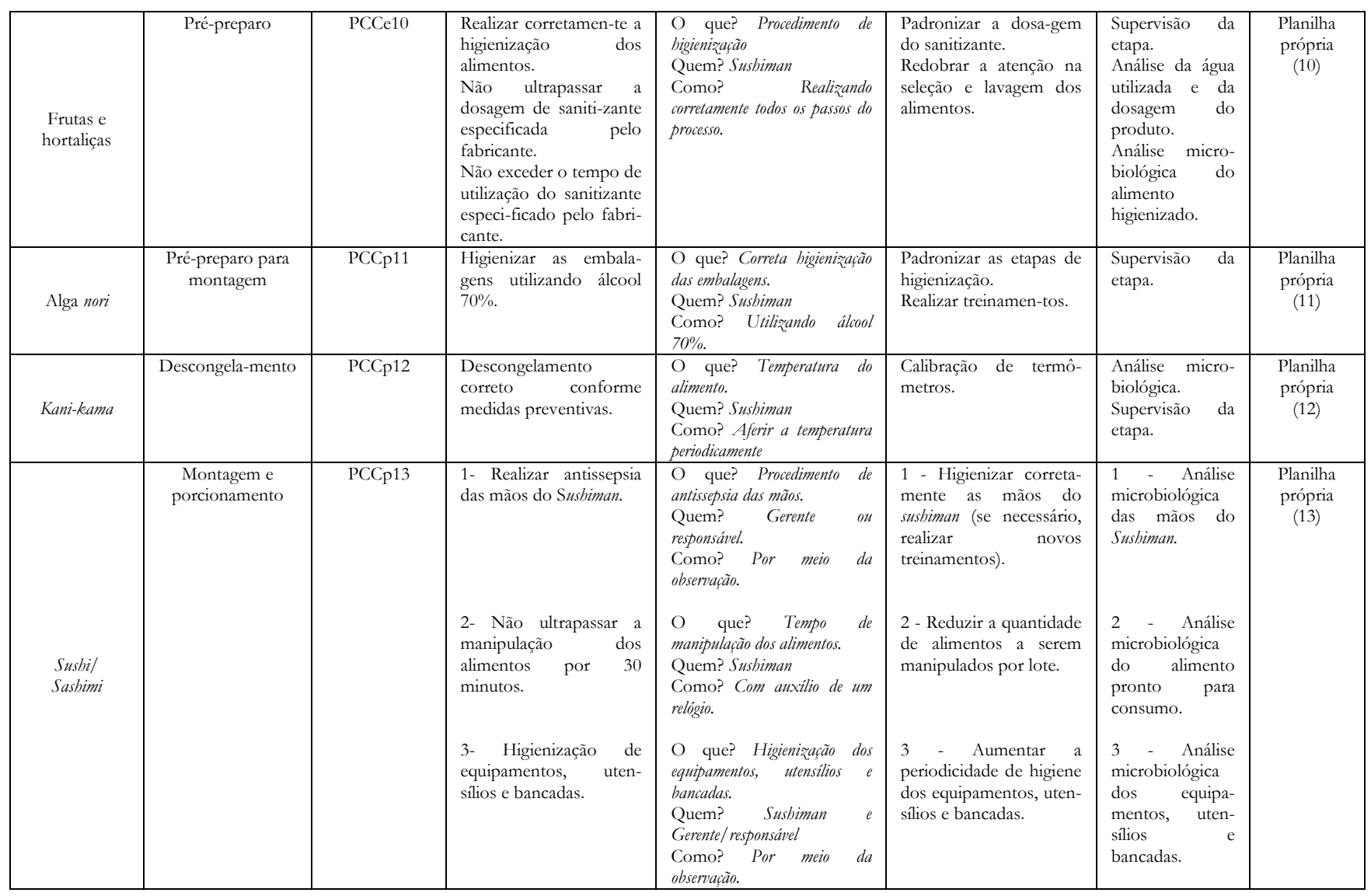

$\mathrm{Na}$ Figura 1, pode-se observar que na elaboração do fluxograma dos sushis, os ingredientes foram separados em seis grupos: pescado cru; arroz japonês; camarão e polvo; frutas e hortaliças; alga nori e; kani-kama. Vale ressaltar que os diversos tipos de sushis preparados neste restaurante resultam da combinação destes ingredientes, podendo incluir somente alguns destes. Os ingredientes são previamente preparados, para que no momento de realização do pedido pelos consumidores, o sushi possa ser montado, porcionado e distribuído ao cliente. $\mathrm{O}$ frescor dos alimentos, principalmente dos pescados, é característico da culinária japonesa. Portanto, estas preparações somente são elaboradas após a avaliação das características organolépticas de todos os ingredientes.

O pescado cru é o alimento de maior preocupação para a saúde do consumidor. Nota-se que este não possui etapa de eliminação de contaminantes microbiológicos (PCCe) e para tal, todos os procedimentos que antecedem sua distribuição devem preservar sua inocuidade por meio das boas práticas, destacando-se as medidas preventivas constantes no Quadro 1. Os procedimentos de higiene dos manipuladores, equipamentos, utensílios e bancadas, e armazenamento sob refrigeração por tempo determinado do pescado cru, devem ser constantemente monitorados.

Constantes no Quadro 2, os PCC do pescado cru encontram-se na etapa de pré-preparo (PCCp1) e espera para montagem do sushi ou sashimi (PCCp2). Importante mencionar que o frescor do pescado é primordial para a qualidade higiênico-sanitária da preparação [5], por isto, os pescados não são reutilizados no dia seguinte e muitas vezes passam pela etapa de pré-preparo durante o período de maior movimento de clientes no restaurante. Ao final da noite, as sobras de pescado cru são incluídas em outras preparações cozidas, grelhadas ou fritas do restaurante, destacando-se a importância das BP durante todo o processo. 
A literatura aponta para o recebimento de pescados crus em condições higiênico-sanitárias inadequadas. $\mathrm{Na}$ fase de recebimento dos pescados, devem ser observadas as características organolépticas dos alimentos (pele lisa, olhos vivos e carne consistente) e a temperatura do alimento, que deve estar entre 2 e $3^{\circ} \mathrm{C}$. No estudo de Rocha et al. [23], os autores observaram que $97,3 \%$ do atum e $96,9 \%$ do namorado recebidos em restaurantes japoneses estavam em temperaturas superiores a $4^{\circ} \mathrm{C}$ (de acordo com a legislação vigente no período do estudo). Já no estudo de Rodrigues et al. [22], 100\% das amostras de pescados recebidos apresentaram temperatura acima de $4^{\circ} \mathrm{C}$.

$\mathrm{O}$ arroz japonês é cozido em uma panela elétrica própria para arroz (PCCe3). Após cozido, deve ser resfriado e refrigerado (PCCp4), para aguardar a montagem do sushi (PCCp5) (Figura 1 e Quadro 1). $\mathrm{Na}$ etapa de preparo, ao atingir $74^{\circ} \mathrm{C}$ no centro geométrico do alimento, os possíveis patógenos podem ser eliminados, prevenindo a ocorrência de DTAs. Nas etapas de resfriamento e espera para montagem, se os critérios de tempo e temperatura do alimento não forem corretamente monitorados, podem possibilitar a proliferação de microrganismos patogênicos, que poderão contaminar os outros ingredientes na etapa de montagem do sushi. No susbibar estudado, o arroz pronto era mantido na panela em um período superior à $8 \mathrm{~h}$, sem qualquer controle de temperatura. Após o término do dia, a sobra de arroz era descartada.

O camarão e polvo são previamente cozidos (PCCe6), resfriados (PCCp7) e congelados em pequenos lotes, o fluxograma de sua produção está especificado na Figura 1. Antes de iniciar as atividades do restaurante, estes alimentos são descongelados (PCCp8), em pequenos lotes, para evitar a contaminação e possíveis sobras. Durante sua espera para montagem (PCCp9) devem-se respeitar os critérios de tempo e temperatura para garantir a qualidade higiênico-sanitária e frescor dos pescados cozidos.

Pode-se observar que a cocção é a única etapa em que o perigo pode ser eliminado (PCCp6), por isto, a temperatura mínima exigida de $74^{\circ} \mathrm{C}$ no centro geométrico do alimento deve ser rigorosamente alcançada. As etapas seguintes (PCCp7, PCCp8 e PCCp9) deverão ser realizadas corretamente (Quadro 1 e 2), com a finalidade de controlar os possíveis microrganismos restantes e evitar a contaminação dos alimentos. No restaurante estudado, apesar de não haver controle de temperatura por meio de termômetros, observou-se que todas as etapas eram realizadas corretamente, utilizando-se o refrigerador para resfriar e descongelar os alimentos.

As frutas e hortaliças cruas devem passar pelo processo de pré-preparo, que consiste na sua higienização (PCCe10). Nesta etapa, deve-se utilizar sanitizantes certificados pelo Ministério da Saúde, respeitando a dosagem e tempo especificados pelo fabricante $[9,27]$.

Conforme especificado no Quadro 1, a higienização das frutas e hortaliças deve contemplar a lavagem criteriosa com água potável; desinfecção, utilizando-se solução clorada ou sanitizantes próprios para este fim e; o enxágue em água potável [?]. Entretanto, observou-se que o sushiman somente realizava a lavagem criteriosa das frutas e hortaliças, sem utilizar sanitizantes.

A utilização de sanitizantes segundo as recomendações acima, é a única etapa em que o perigo presente nas frutas e hortaliças pode ser eliminado. A literatura aponta para a comercialização de frutas e hortaliças frequentemente contaminadas por enteroparasitas e microrganismos patogênicos como os coliformes fecais, Salmonella spp, Escherichia Coli, Staphylococcus spp, entre outros [28,29,30], reafirmando a necessidade da correta higienização destes alimentos. Gonzalez et al. [31] realizaram estudo com manipuladores de alimentos de restaurantes de SantosSP e verificaram que somente $19 \%$ conheciam os procedimentos de correta higienização de hortifrútis. No presente estudo, o sushiman desconhecia o correto procedimento de higiene das frutas e hortaliças.

A alga nori é comercializada em embalagem fechada e deve ser mantida em temperatura ambiente. Sua utilização deve ocorrer de acordo com as recomendações da embalagem, respeitando a data de validade do produto. A preocupação de sua qualidade higiênico-sanitária volta-se para a correta higienização da embalagem antes de ser aberta para uso (PCCp11).

De acordo com a legislação vigente [9], a embalagem deve ser higienizada utilizando-se um sanitizante, que pode ser o álcool 70\%. Esta etapa não era realizada no sushibar estudado. 
O kani-kama é um produto derivado do pescado, comercializado congelado. Deve ser recebido em temperatura adequada, respeitando as recomendações da embalagem ou, quando ausente, deve estar a $-12^{\circ} \mathrm{C}$ ou menos. Foi identificado um PCC na etapa de descongelamento do alimento (PCCP12), que deve ocorrer preferencialmente em ambiente refrigerado (até $5^{\circ} \mathrm{C}$ ). Após aberta a embalagem, deve respeitar os critérios de armazenamento descritos na mesma. No sushibar estudado, o kani-kama era descongelado em um refrigerador.

A última etapa da cadeia de produção do sushi consiste na união dos ingredientes, de acordo com o tipo de sushi solicitado pelo cliente. Alguns tipos de sushis podem incluir determinadas frutas e/ou hortaliças, e/ou utilizar somente o camarão cozido, o polvo cozido ou o peixe cru.

A etapa de montagem e porcionamento (PCCp13) do sushi e do sashimi (somente o pescado cru), merece especial atenção para não haver contaminação cruzada dos alimentos, pelas mãos do sushiman, pelos equipamentos, utensílios e bancadas utilizadas. É importante que os ingredientes sejam retirados da refrigeração em lotes e sejam manipulados em temperatura ambiente por no máximo 30 minutos [9]. Raramente ocorre espera para a distribuição destas preparações em restaurantes de culinária japonesa, pois são preparadas conforme solicitação do cliente. Entretanto, em outros locais como supermercados e restaurantes comuns, pode haver espera, e, portanto, devem ser respeitados os tempos e temperaturas, ou seja, $10^{\circ} \mathrm{C}$ até 4 horas ou entre 10 e $21^{\circ} \mathrm{C}$ por até 2 horas (Quadro 1).

Durante todo o preparo dos alimentos, algumas condutas são importantes, como a correta higiene das mãos do manipulador, controle do binômio tempo e temperatura de todas as etapas, correta higienização de frutas e hortaliças, bancadas e utensilios.

A correta higiene das mãos do manipulador previne a contaminação destes alimentos que são bastante manipulados durante todo o seu preparo e serão consumidos crus. Foi observado que durante a manipulação dos alimentos, o sushiman do restaurante estudado não realizou a correta antissepsia das mãos, que deve ser realizada conforme a CVS-5/2013 [9], da seguinte maneira: umedecer as mãos e antebraços com água; lavar com sabonete líquido, neutro, inodoro e com ação antisséptica; massagear bem as mãos, antebraços, entre os dedos e unhas, por pelo menos 3 minutos; enxaguar as mãos e antebraços e secá-los com papel toalha descartável não reciclado ou outro procedimento não contaminante, e coletor de papel acionado sem contato manual. Além disto, os produtos de higiene com ação antisséptica devem ser aprovados pela Agência Nacional de Vigilância Sanitária.

Em adição, de acordo com a CVS-5/2013 [9], é obrigatória a presença de lavatórios exclusivos para higiene das mãos, sabonete antisséptico e toalhas de papel não reciclado na área de manipulação de alimentos. Neste caso, a área do sushibar deve conter seu lavatório de mãos exclusivo. Acrescenta-se, que o restaurante estudado continha um lavatório de mãos exclusivos na área do Sushibar, entretanto, não continha os materiais necessários para a correta higienização, sendo a lavagem das mãos realizada com detergente líquido e a secagem realizada em panos. Além disto, o sushiman declarou não conhecer o procedimento de higienização correta das mãos.

Notou-se a necessidade do sushiman aumentar a frequência de higiene das mãos, principalmente ao manipular alimentos diferentes, conforme disposto na legislação [9]. No estudo de Miranda \& Baião [32], que encontrou baixa frequência de higiene das mãos, 2 entre os 8 esfregaços da superfície das mãos dos subimen apresentaram a presença de coliformes totais e Escherichia Coli.

O controle da temperatura sob forma de refrigeração é uma etapa de prevenção da multiplicação de microrganismos. Os ingredientes devem ser mantidos sob refrigeração e posteriormente, os sushis e sashimis prontos para consumo. Para o controle da temperatura, o sushibar deve conter um termômetro e aferir periodicamente a temperatura dos alimentos e equipamentos de refrigeração, que devem receber manutenção periódica [9,27]. No presente estudo, não foi observada a presença de termômetros, como no estudo de Valejo et al. [33], em que os autores vistoriaram 52 estabelecimentos em Presidente Prudente(SP) e observaram a ausência de termômetros na maior parte dos estabelecimentos.

O binômio tempo e temperatura da exposição dos alimentos durante todo o fluxo produtivo deve ser respeitado para não proporcionar aos microrganismos condições favoráveis para a sua proliferação. Gottardi et al. [34], realizaram um estudo sobre o perfil epidemiológico da ocorrência de surtos 
de DTAs e, dentre os fatores predisponentes aos surtos, o mais frequente foi a temperatura inadequada de refrigeração, evidenciando que o controle da temperatura dos alimentos deve ocorrer desde a recepção dos ingredientes até a distribuição do alimento pronto para consumo. Como o sushibar não continha termômetros, não foi observado o controle do binômio tempo e temperatura dos alimentos.

Outro aspecto importante é a correta higienização de utensílios e equipamentos, que deve ser realizada antes e depois de cada etapa de preparo, e quando julgar necessário. Segundo a CVS-5/2013 [9], deve ser realizada da seguinte forma: remoção de sujidades; lavagem com água e sabão ou detergente; enxágue; desinfecção química seguida de enxágue final, ou desinfecção física pelo emprego de vapor. Os produtos utilizados na desinfecção devem ser registrados no Ministério da Saúde. No sushibar estudado, a higiene dos utensílios e equipamentos era realizada somente com água e detergente, não havendo etapa de desinfecção.

A culinária japonesa possui algumas características peculiares, onde se inclui a utilização de utensílios de madeira, como colher de bambu para a preparação do arroz japonês, facas com cabo de madeira e esteirinha de bambu para enrolar os sushis ${ }^{[5]}$. De acordo com a legislação, a utilização de utensilios com este tipo de material é proibida, pois são considerados materiais adequados à proliferação de microrganismos e assim, propiciam a contaminação dos alimentos [9]. No município de São Paulo, já existe uma portaria (no 2.535/03, de 24/10/2003) [35] que estabelece exceção na utilização deste tipo de material em preparações reconhecidamente típicas, nacionais e internacionais.

Como a portaria é vigente no município de São Paulo, os outros municípios nacionais ainda devem se adequar às legislações nacionais. Assim, os sushibares devem trocar as colheres e facas de bambu por materiais não porosos, e como sugestões, a esteirinha pode ser trocada por outro material, como o tapete de silicone, que possui a mesma flexibilidade, ou ser coberta com filme plástico que deve ser trocado constantemente.

O uniforme do sushiman, de acordo com a cultura japonesa, é composto de kimono e faixa na cabeça (batimake). Os kimonos devem ser de cores claras e tecidos leves, para que não proporcionem calor ao sushiman e induzam à falta de higiene, como a limpeza do suor com as mãos, antebraços ou no próprio kimono. Além do hatimake, a rede protetora dos cabelos não deve ser dispensada.

Para proporcionar tranqüilidade, característica dos japoneses, os restaurantes possuem iluminação fraca, porém, o estabelecimento deve atentar para que a área do sushibar tenha iluminação suficiente para não atrapalhar o fluxo do processo, a correta higienização de alimentos, mãos, utensilios e equipamentos, e evitar acidentes.

As adequações de procedimentos e atitudes relacionados às peculiaridades da culinária japonesa, como a troca de determinados equipamentos e utensílios, uso de redes protetoras para cabelos, ou melhoria da iluminação do ambiente, apesar de proporcionarem maior segurança ao sushiman e melhor qualidade higiênico-sanitária das preparações, podem descaracterizar as preparações típicas. São estas características que diferem a culinária japonesa das outras culinárias do mundo, tornando o sushi e o sashimi, um patrimônio gastronômico ${ }^{[1,2]}$.

É importante atentar não somente para a qualidade higiênico-sanitária das preparações, mas também à qualidade simbólica destes alimentos, que está associada ao significado para o indivíduo, inscrevendo-se em um quadro cultural e numa visão de mundo particular $[27,36,37]$.

Neste sentido, a escolha por preparações túpicas, como o sushi e o sashimi, é realizada não somente com o intuito de nutrir-se, mas como tentativa de vivenciar hábitos e costumes da população japonesa [37].

\section{CONCLUSÃO}

O Plano APPCC apresentado identificou treze PCC na elaboração de sushis e sashimis, que devem ser monitorados constantemente, pois representam garantia na qualidade higiênico-sanitária destas preparações.

O consumo de pescado cru constitui preocupação, pois no seu preparo não há etapa de eliminação do perigo, desta forma, as medidas preventivas como higiene das mãos, equipamentos e utensílios, e controle da temperatura devem ser realizados corretamente. Entretanto, as observações realizadas no sushibar estudado revelaram 
procedimentos de higiene inadequados, como a ausência de controle do binômio tempo e temperatura, inadequada higiene das mãos, hortifrútis, utensilios e equipamentos, além da ausência de treinamentos sobre os temas.

O treinamento e a supervisão do sushiman são estratégias para efetividade do cumprimento das medidas preventivas. Para tal, devem ser realizados periodicamente por profissionais capacitados.

Conhecer as etapas de produção de sushis e sashimis torna-se importante para adequar sua produção à legislação vigente, proporcionando ao cliente um alimento seguro e saudável. Entretanto, os hábitos e costumes dos japoneses devem integrar esta análise, pois, algumas mudanças podem ser realizadas, sem descaracterizar a preparação e tradição da culinária japonesa.

Assim, manter as tradições e características culturais nas preparações típicas pode ser um desafio, pois as leis vigentes não contemplam as peculiaridades destas preparações [27]. Para tanto, os autores sugerem a elaboração de leis específicas para o controle higiênico-sanitário de preparações regionais, como os pratos típicos da culinária japonesa. Estas leis devem ser elaboradas com a finalidade de reduzir os riscos à saúde do consumidor, contemplando peculiaridades de cada patrimônio gastronômico.

Reconhece-se que o presente estudo apresenta como limitação, a análise dos principais ingredientes utilizados no preparo de sushis e sashimis de um único sushibar. Outros sushibares podem incluir em suas preparações ingredientes diferentes, não contemplados neste estudo. Entretanto, considera-se a importância deste estudo para o início da discussão sobre um Plano APPCC apresentado aos principais ingredientes destas preparações. Sugere-se a avaliação higiênico-sanitária de uma amostra representativa de sushibares, para agregar informações relevantes aos procedimentos constantes no Plano APPCC elaborado.

\section{REFERÊNCIAS}

[1] Hernández JC. Patrimônio e Globalização: o caso das culturas alimentares. In: Canesqui AM, Diez-Garcia RW. Antropologia e nutrição: um diálogo possível. Rio de Janeiro: Editora FIOCRUZ; 2005. p. 129-146.
[2] Silva AB, Soares ALR, Wolf RA. Registro da gastronomia japonesa como patrimônio imaterial dos nikkeis residentes no Brasil. Mouseion. 2011;10:150-157.

[3] Proença RPC. Alimentação e globalização: algumas reflexões. Cienc Cult. 2010;62(4):43-47.

[4] Consulado Geral do Japão, Imigração Japonesa no Brasil. A história da imigração japonesa no Brasil: as famílias. São Paulo; 2003.

[5] Medina I. As cozinhas do Japão. São Paulo: Moderna; 2006. p. 08-12.

[6] Barber K, Takemura H. Sushi - Taste and Technique. New York: Dorling Kindersley- Civilização Editores Ltd.; 2008.

[7] Uggioni PL, Proença RPC, Zeni LAZR. Assessment of gastronomic heritage quality in traditional restaurants. Rev. Nutr. 2010;23(1):7-16.

[8] Brasil. Ministério da Cultura e Aquicultura [internet]. Consumo de pescado no Brasil aumenta 23,7\% em dois anos [publicado em 17 out 2013] [acesso em 08 mar 2014]. Disponível em: http://www.mpa.gov.br

[9] São Paulo. Secretaria de Estado da Saúde. Portaria CVS no 05 , de 09 de abril de 2013. Aprova o regulamento técnico sobre boas práticas para estabelecimentos comerciais de alimentos e para serviços de alimentação, e o roteiro de inspeção, anexo [internet]. [acesso em 07 de mar 2014]. Disponível em: http://crn3.org.br/legislacao

[10] Organização Pan-Americana da Saúde. Codex Alimentarius. Higiene dos Alimentos - Textos Básicos [internet]. Brasília; 2006 [acesso em 14 dez 2013]. Disponível em: http://www.anvisa.gov.br/divulga/public/alimentos

[11] Ministério da Saúde (BR). Portaria no 1.428, de 26 de novembro de 1993. Dispõe sobre o controle de qualidade na área de alimentos. Diário Oficial da União. 02 dez 1993; Seção I: 18415-18419.

[12] Rosa LS, Queiroz MI. Avaliação da qualidade do leite cru e resfriado mediante a aplicação de princípios do APPCC. Food Sci Technol. 2007;27(2):422-430.

[13] Hojeije KY. APPCC no plantio e na industrialização do palmito. Necessidade ou obrigação? Higiene Alimentar. 2006;20:16-19.

[14] Jin S, Zhou J, Ye J. Adoption of HACCP system in the Chinese food industry: A comparative analysis. Food Crontrol. 2008;19(8):823-828. 
[15] Casani S, Knochel S. Application of HACCP to water reuse in the food industry. Food Control. 2002;13(4-5):315327.

[16] Rodrigues FA, Nascimento DA, Cavichioli D, Souza AM. Identificação de pontos críticos de controle de preparações protéicas, em uma unidade de alimentação e nutrição. Higiene alimentar. 2011;25(192-193):49-55.

[17] Rodrigues KL, Silva JA, Aleixo JAG. Efeito da aplicação da Análise de Perigos e Pontos Críticos de Controle (HACCP) programa de pré-requisito em uma unidade de food service institucional no Sul do Brasil. Food Sci. Technol. 2012;32(1):196-200.

[18] Roncesvalles G, Vitas AI, Díez-Leturia M, García-Jalón I. Food safety and the contract catering companies: Food handlers, facilities and HACCP evaluation. Food Control. 2011;22(12):2006-2012.

[19] International Commission on Microbiological Specifications for Foods. Ecologia microbiana de los alimentos, v.1: Factores que afetam a la sobrevivência de los microrganismos em los alimentos. Zaragoza; 1980.

[20] Santos CAML, Vieira RHSF. Bacteriological hazards and risks associated with seafood consumption in Brazil. Rev. Inst. Med. Trop. São Paulo. 2013;55(4):219-28.

[21] Menezes FGR, Silva CM, Carvalho FCT, Sousa DBR, Vieira RHSF. Salmonella e staphylococcus coagulase positiva em sushis e sashimis comercializados na cidade de Fortaleza, Ceará. In: Anais do II Simpósio de Controle do Pescado - SIMCOPE [internet]: 2006 [acesso em 05 nov 2013]. Disponível em: http://www.ftp.sp.gov.br/ftppesca/ IIsimcope/402.pdf.

[22] Rodrigues BL, Santos LR, Mársico ET, Camarinha CC, Mano SB, Conte Junior CA. Qualidade físico-química do pescado utilizado na elaboração de sushis e sashimis de atum e salmão comercializados no município do Rio de Janeiro, Brasil. Semina: Ciencias Agrárias. 2012;33(5):1847-1854.

[23] Rocha AF, Moraes ML, Feijó MBS. Avaliação do estado de frescor do pescado entregue em uma unidade de alimentação e nutrição. Higiene Alimentar. 2009;23:171-175.

[24] Mársico ET, Oliveira CM, Ferreira PV, Antunes L, Sobreiro LG. Avaliação da qualidade de sushis e sashimis comercializados em shopping centers. Higiene Alimentar. 2006;20(147):63-65.

[25] Huang $\mathrm{Y}$, Liang J, He H. Analysis on sanitary microbiology control of dealing with sushi. Chinese Journal of Health Laboratory Technology. 2009;03.
[26] Atanassova V, Reich F, Klein G. Microbiological Quality of Sushi from Sushi Bars and Retailers. J Food Prot. 2008;4:676-873.

[27] Brasil. Resolução de Diretoria Colegiada no 216, de 15 de setembro de 2004. Estabelece procedimentos de Boas Práticas para serviços de alimentação a fim de garantir as condições higiênico-sanitárias do alimento preparado [internet]. [acesso em 05 nov 2013]. Disponível em: http://e-legis.anvisa.gov.br/leisref/public

[28] Bobco SE, Pierozan MK, Cansain RL, Oliveira D, Pinheiro TLF, Toniazzo G. Condições higiênicas de alfaces (Lactuca sativa) comercializadas na cidade de Erechim - RS. Alim. Nutr. 2011;22(2):301-305.

[29] Teixeira LEB, Santos JEF, Moreira IS, Sousa FC, Nunes JS. Qualidade microbiológica de frutas e hortaliças comercializadas na cidade de Juazeiro do Norte - CE. Revista Verde. 2013;8(3):23-26.

[30] Ferro JJB, Costa-Cruz JM, Barcelos ISBC. Avaliação parasitológica de alfaces (Lactuca sativa) comercializadas no município de Tangará da Serra, Mato Grosso, Brasil. Rev Patol Trop. 2012;41(1):47-54.

[31] Gonzalez CD, Perrella NG, Rodrigues RL, Gollucke APB, Schattan RB, Toledo LP. Conhecimento e percepção de risco sobre higiene alimentar em manipuladores de alimentos de restaurantes comerciais. Nutrire. 2009;34(3):4556.

[32] Miranda ACB, Baião RCL. Avaliação das boas práticas de fabricação de preparações a base de pescados crus em restaurante japonês. C\&D - Revista Eletrônica da Fainor, 2011;4(1):52-61.

[33] Valejo FAM, Andrés CR, Mantovan FB, Rister GP, Santos GD, Andrade FF. Vigilância sanitária: avaliação e controle de qualidade dos alimentos. Higiene Alimentar. 2003;17(106):16-21.

[34] Gottardi CPT, Souza CAS, Schimidt V. Surtos de toxinfecção alimentar e a evolução das DTAs ocorridos no município de Porto Alegre, no período de 1995 a 2002. Higiene Alimentar. 2006;20(143)50-55.

[35] São Paulo. Secretaria Municipal de Saúde. Portaria no 2535/03, de 24 de outubro de 2003. Aprova o regulamento técnico para controle higiênico-sanitário em empresas de alimentos, estabelecendo critérios e parâmetros para a produção de alimentos e bebidas, aplicadas a indústria de alimentos. São Paulo; 2003. 
[36] Poulain JP, Proença RPCP. Reflexões metodológicas para o estudo das práticas alimentares. Rev. Nutr. 2003;16(4):365-366.
[37] Garcia RWD. Reflexos da globalização na cultura alimentar: considerações sobre mudanças na alimentação urbana. Rev. Nutr. 2003;16(4):483-492. 